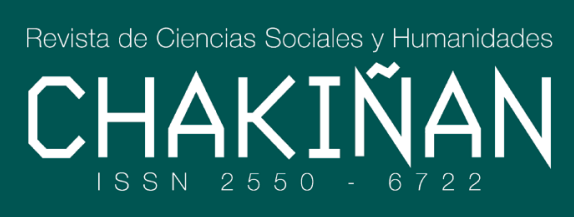

Número 14 / AGOSTO, 2021 (130-145)

Hugo Germán González Toapanta

Investigador independiente, Riobamba, Ecuador.

hugergont@yahoo.es

ORCID:

https://orcid.o rg/0000-0003-3221-1788

\section{PANDEMIAS EN LA HISTORIA: LA PESTE NEGRA Y LA GRIPE ESPAÑOLA, COVID-19 Y CRISIS CAPITALISTA}

PANDEMICS IN THE HISTORY: THE BLACK DEATH AND THE SPANISH FLU, COVID-19 AND CAPITALIST CRISIS

DOl:

https://doi.org/10.37135/chk.002.14.09

Artículo de Reflexión
Recibido:

(29/06/2020)

Aceptado:

(26/11/2021)

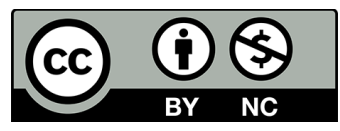




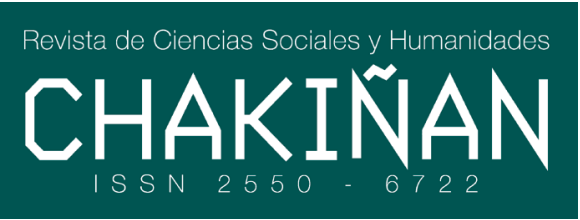

Número 14 / AGOSTO, 2021 (130-145)
PANDEMIAS EN LA HISTORIA: LA PESTE NEGRA Y LA GRIPE ESPANOLA, COVID-19 Y CRISIS CAPITALISTA

PANDEMICS IN THE HISTORY: THE BLACK DEATH AND THE SPANISH FLU, COVID-19 AND CAPITALIST CRISIS

\section{Resumen}

En el momento de crisis sanitaria, económica, política y social que atraviesa la humanidad, es importante recurrir a los hechos históricos y contrastarlos con la realidad actual, para de esta manera tener mayores argumentos interpretativos y de conocimiento sobre la misma. En esa línea, este artículo tiene como objetivo realizar un análisis de las consecuencias que trajeron para la humanidad, tanto la peste negra como la gripe española, así como los efectos que la Covid-19 hoy causa en algunos países en el marco de una crisis del capitalismo. De esta manera, será un aporte a los innumerables debates que sobre el tema se han ejercido en los diferentes campos, dentro y fuera de la academia. Su metodología se centra en recoger los aportes investigativos que se han realizado respecto a sus temáticas para llegar a un análisis cualitativo y comparativo de los efectos causados a la humanidad. Las pandemias estudiadas produjeron varias consecuencias sociales, económicas y políticas en el devenir histórico que posibilitaron a su vez ciertos cambios en las sociedades. La Covid-19, por su parte, ha evidenciado las debilidades del sistema capitalista en su forma neoliberal, varios países que han recurrido a la aplicación de este modelo no han podido sostener de una manera eficaz la emergencia sanitaria.

Palabras clave: Plaga, gripe española, pandemia, capitalismo, neoliberalismo

\begin{abstract}
Nowadays, when humanity is facing a health, economic, political and social crisis, it is essential to go back to historical facts and contrast them with the real situation, in order to have a better interpretation and understanding of this reality. Therefore, this paper pretends to analyze the consequences that the Black Death and the Spanish Flu had on humanity, along with the effects that Covid-19 is currently causing in some countries, in the context of a crisis of capitalism. In this way, it is a contribution to the numerous debates that have been taking place on this matter in different fields, both inside and outside the academy. Its methodology is based on the compilation of research contributions that have been carried out on these topics in order to develop a qualitative and comparative analysis about the effects caused to humanity. The pandemics studied had a number of social, economic and political consequences during the historical development that allowed to bring certain changes in society. Covid-19, on the other hand, has revealed the weaknesses of the capitalist system in its neoliberal form: several countries that have applied this model to addressing the pandemic, have not been able to deal effectively with the health emergency.
\end{abstract}

Keywords: Plague, Spanish $f$, pandemic, capitalism, neoliberalism 


\section{INTRODUCCIÓN}

A lo largo de la historia, la humanidad ha soportado diferentes pandemias y epidemias que han causado millones de muertes en la población y han conllevado múltiples consecuencias sociales, económicas y políticas. Desde el Medioevo, pasando por los albores y finales del siglo XX, para finalmente llegar a la enfermedad de Covid-19, estas han dejado huellas imborrables en la vida del planeta y sus habitantes.

En este momento de crisis sanitaria, económica, política y social que vivimos, es importante recurrir a los hechos históricos y contrastarlos con la realidad actual, para de esta manera tener mayores argumentos interpretativos $\mathrm{y}$ de conocimiento sobre la misma. Refrescar la memoria y a la vez cuestionar sobre lo que se está haciendo, deben impedir un tanto que la vida y la naturaleza se destruyan, no solo por efecto de estas pandemias, sino también por el poder destructivo del capitalismo en sus diferentes fases.

A continuación, se reflexiona sobre dos importantes pandemias, la peste negra y la gripe española, indagadas a la luz de lo que el mundo vive en los actuales momentos con la Covid-19. En el caso de la peste negra medieval, algunas investigaciones la sitúan como una de las grandes pandemias de la historia por su grado de mortalidad, y su gran repercusión para el fin del feudalismo, al ofrecer el golpe final a una economía europea maltrecha. Según el estudio de Benedictow (2011), el comercio fue vencido por la enfermedad.

El contexto de la Gran Guerra permite el aparecimiento de otra de las pandemias que arrasó con gran cantidad de vidas humanas, la mal llamada gripe española. Esta tardó cerca de tres años para llegar a la mayoría de los países del orbe, y en ciertos casos evidenció la importancia de los medios de comunicación para evitar mayores desastres. La presencia de la gripe pudo motivar que diferentes países se preocuparan más por renovar sus instituciones de salubridad.

Sobre esta enfermedad se han escrito varios artículos, libros e investigaciones desde diferentes campos, que han permitido ubicar mejor la situación vivida por poblaciones de varios países de la región y las consecuencias que trajo. Echeverri (1993) sostiene que en España ha sido poco investigada, a pesar de la gran mortandad que causó en dicho país, sin embargo, en los últimos años han ido aumentando dichas investigaciones. En otro estudio, el historiador ecuatoriano Germán Rodas (2015) analiza su paso por el Ecuador, y la labor que cumplieron medios de comunicación internacionales $y$ locales para evitar su propagación.

Investigaciones desde el campo de la demografía, epidemiología e historia de la medicina, han buscado respuestas múltiples a las varias interrogantes que dejó la gripe; quizá la inquietud más importante es poder descifrar nuevas posibilidades de aparecimiento de un caso similar de esta enfermedad, por lo tanto, su interés investigativo va más allá del aspecto estrictamente histórico. La particularidad de esta pandemia respecto a la peste negra es que se presentó en tres olas con incidencias epidémicas diferentes.

Este pequeño recorrido histórico permite llegar a los actuales momentos en que la sociedad se enfrenta a la presencia de la Covid-19, pandemia rodeada de varias incógnitas, respecto a su origen y estragos de su infección. Más allá de estas implicaciones, este artículo centra su estudio y análisis en su contexto económico y político societal, que nos permita entender más profundamente sus consecuencias y complicidades sistémicas, siempre mirando las enseñanzas que el pasado nos dejó.

El contexto de su aparecimiento es la presencia en varios países de América Latina de una serie de movilizaciones realizadas por varios sectores sociales perjudicados o excluidos por la aplicación de medidas neoliberales de 
gobiernos afines con este modelo. Esto sucedía en Chile, Ecuador, Colombia, Haití, entre otros países. El capitalismo globalizado, en los últimos años, ha implementado una serie de mecanismos económicos y políticos para superar sus diferentes crisis y renovar su forma de dominación mundial.

En ese escenario global aparece el coronavirus, en medio de una crisis del neoliberalismo cuya cabeza más visible son los EE. UU., y la presencia de China como una nueva fuerza económica y política con afanes hegemónicos, cuyo papel fue fundamental para sacar a las economías de la catástrofe generada por la crisis de 2008. Punto importante es el rol que juega el Estado no solo en cada país, sino también en la mundialización de la economía.

La pandemia generada por la presencia de la Covid-19 no solo ha permitido acelerar una recesión en curso, afectando a los derechos sociales de las mayorías, sino que también ha evidenciado las flaquezas del sistema, dejando caer el peso de la crisis en los sectores más vulnerables. Como en otras ocasiones los organismos internacionales de crédito (FMI, Banco Mundial), en complicidad con los sectores dominantes de cada país, han acudido a políticas de ajuste y a restar la eficacia del Estado para resolver los problemas del capitalismo.

En Ecuador y en varios países de América Latina la situación es clara. Los diferentes sistemas de Salud Pública llegaron a colapsar y no pudieron dar respuestas eficaces a la emergencia sanitaria. Los continuos recortes presupuestarios realizados por el gobierno de Lenin Moreno desde sus inicios, tanto en salud como en educación, permitieron comprender la magnitud de la crisis y sus consecuencias sociales y políticas, entre otras, despidos laborales y baja calidad en los servicios públicos, tomando como justificativo para su privatización y precarización del costo de vida.

El artículo no centra su análisis en las posibles alternativas que desde algunos sectores sociales se están manifestando, y deja la posibilidad de un estudio más avanzado en el futuro. Frenar la arremetida neoliberal al llegar a las comunidades, familias y pueblos, que bajo diferentes liderazgos apuestan por que otro mundo es posible; fortalecer la soberanía alimentaria desde una agroecología sustentable, retroalimentar el ecofeminismo, apoyar la comercialización directa con los pequeños productores, consumir de manera racional, son, entre otros, aspectos que necesitan ser trabajados posteriormente.

Finalmente, y desde un enfoque histórico-crítico, este trabajo quiere insistir en la importancia del estudio de los hechos históricos, como un aporte para entender los problemas actuales a través del rescate de huellas de la historia, para buscar consensos y acercamientos necesarios entre los públicos diversos, y aupar esfuerzos institucionales en procura de fortalecer el pensamiento crítico actual.

\section{METODOLOGÍA}

Para este estudio se recurrió al método de investigación cualitativa, cuyo rigor científico se basa en la credibilidad, la confiabilidad, la transferibilidad y consistencia de los datos obtenidos para entender los fenómenos que se investigaron. El procedimiento partió de una revisión bibliográfica digital de cada una de las temáticas planteadas. Artículos, ensayos, libros, investigaciones, etc., fueron recolectados y consultados para conseguir la información necesaria, y posteriormente realizar el correspondiente análisis de datos y sintetizar sus resultados y conclusiones.

Utilizando la metodología analítica-sintética, se sigue en parte la pedagogía de Paulo Freire como propuesta teórico-metodológica, que permite recurrir al análisis de la realidad histórica y actual para una acción colectiva, reflexiva y transformadora. En ese hilo conductor, este artículo se inscribe en una línea de reflexión y discusión como un aporte más al debate actual. 


\section{RESULTADOS Y DISCUSIÓN}

\section{LAS PANDEMIAS EN LA HISTORIA}

Las enfermedades, pestes, plagas, epidemias o pandemias son tan antiguas como la historia de la humanidad. Tomasi (2020) indica que, ante su propagación las poblaciones han tenido diferentes reacciones, por ejemplo, en las antiguas culturas se creía que ciertas enfermedades venían como castigos divinos y quienes eran afectados debían ser separados del pueblo para impedir su expansión. El relato bíblico incluso recoge algunas normas o sugerencias para separar a los enfermos de lepra.

Médicos y científicos han contribuido en distintas épocas y han recurrido a diferentes recursos, para saber de la existencia de estas enfermedades pandémicas y de esta manera formular las hipótesis de sus posibles formas de transmisión. Como consecuencia de estos aportes científicos surgen términos relacionados con la salud y la higiene que para nosotros son muy conocidos hoy. Así, fueron apareciendo conceptos como recogimiento, cuarentena, distanciamiento social, etc., todos con sus diferentes costos económicos y sociales.

\section{LA PESTE NEGRA (1347-1382)}

La peste negra se convirtió en una pandemia de tal magnitud que no solo sacudió los cimientos económicos y sociales del Viejo Mundo, sino que cambió el curso de la historia. Tuvo su origen en Asia, se propagó a Europa, y su influencia llegó hasta el norte de África. El contagio llegó por barco, pues en aquellos tiempos empezaron a abrirse nuevas rutas de intercambio, ya que Europa empezaba a tener un avance económico y comercial. El norte de Italia era una zona privilegiada por el auge del comercio, ciudades como Florencia, que empezaba a despegar con varios negocios, fue una de las más afectadas (Haindl 2010).

La expresión Peste Negra ha sido utilizada por varios investigadores para designar a la gran epidemia que asoló principalmente el continente europeo. Según Benedictow (2011) no es hasta los años sesenta del siglo anterior, cuando se empiezan a publicar estudios sobre su difusión y mortandad, dichos análisis aportarán detalles de manera significativa sobre su desplazamiento geográfico, sus características y fundamentalmente, la mortalidad causada y su fuerte impacto histórico.

Nuevos estudios sobre esta epidemia han permitido ahondar aportes desde la economía y la historia local. En su mayoría son datos básicos que requieren de mayor profundización con base en fuentes estrictas que permitan fortalecer el conocimiento en los campos epidemiológico y demográfico (Benedictow 2011). Para algunos cronistas tradicionales su estudio no era importante, pues la epidemia constituía un asunto marginal.

\section{IMPACTO SOCIAL, RELIGIOSO Y ECONÓMICO}

La población de Florencia se redujo en un $20 \%$ en un lapso de dos a tres meses. La sociedad de entonces no estaba preparada para afrontarla y los ricos buscaban alternativas para salvarse. Los pocos médicos que había intentaban buscar la cura con medicinas naturales y no tuvieron buenos resultados.

Fue tal la catástrofe que provocó que la ciudad pasara a formar parte tanto del folklore como de las obras de la gente instruida de la época. El escritor Giovanni Bocaccio entregó a la Literatura su famoso Decamerón que narra en forma de cuentos detalles de lo sucedido en Florencia (Simoni 2007).

Empezaron a existir abandonos sociales por temor al contagio, incluso en las mismas familias. Los temores religiosos también aparecieron. Todo era obra del apocalipsis que estaba por llegar, ante lo cual no se podía hacer nada. La 
Iglesia echó la culpa a la decadencia moral de la sociedad y se refugió en la creencia del castigo divino. La argumentación papal decía que la salvación estaba en ser fieles a la fe a través de la oración y las manifestaciones religiosas. Nada de eso funcionó. La Iglesia católica perdía a sus devotos y su poder acumulado hasta entonces.

En Florencia sucedió algo parecido con la Guayaquil actual en Ecuador, abundaron los muertos en las calles y las autoridades civiles y eclesiásticas vieron como única opción la construcción de más cementerios. Aunque la epidemia afectó a ricos y a pobres, las causas para su propagación, fundamentalmente, eran la falta de atención a los sectores más vulnerables, pues la gente pobre vivía en pésimas condiciones higiénicas, con una mala alimentación y con poca atención en salud.

Algunos investigadores han concluido que la peste negra, por todos sus efectos sociales, incidió más en los medios urbanos. Sin embargo, otros como Romano y Tenenti piensan que es imposible determinar con exactitud en dónde se sintieron más los efectos, si en la ciudad o en el campo, puesto que la mayoría de muertos en las ciudades correspondieron a campesinos inmigrantes, y una parte de los fallecidos en el campo fue gente que salió huyendo de las ciudades (Romano y Tenenti 1977).

Las consecuencias sociales y económicas tuvieron una importante repercusión en el devenir histórico de las sociedades, al constituirse en una de las mayores catástrofes demográficas de la humanidad, desencadenando o agravando la crisis económica y social que vivió Europa entre los siglos XIV y XV.

En lo económico la mayoría de los autores centran su explicación en la gran recesión que causó: aumento de precios, bajos salarios, tensiones sociales, crisis agraria que produjo disminución de las rentas agrícolas y caída de precios. Esto último marcó el fin de la época agraria y el predominio de la ciudad (Tomasi 2020). Sin embargo, en varias partes del continente transformó la vida de los campesinos, aumentó su población y provocó un mayor equilibrio entre la tierra y la población. El feudalismo empezaba su declive y con ello el temor de sus sostenedores, el clero y los señores feudales.

El medioevo vivía los inicios de una desestabilización política y social, el arte y las ciencias empezaban a tomar la iniciativa de esos cambios, dando paso a las primeras manifestaciones del Renacimiento europeo. El campesinado adoptó nuevas formas de negociación, sin trabajos forzados, con nuevos salarios, otros ocuparon los puestos de los muertos de la ciudad. Los sectores dominantes veían cómo se desmoronaban los cimientos de su poder y soportaron varias revueltas. Para muchos esta peste marcó el inicio del mundo moderno, donde la servidumbre feudal fue desapareciendo gradualmente.

\section{LA GRIPE ESPAÑOLA (1918-1920)}

En 1918, mientras el mundo empezaba a salir de las ruinas de la Gran Guerra, algunos países fueron azotados por una singular enfermedad conocida como la gripe española. Por la cantidad de muertos que produjo, esta ha sido catalogada como una de las peores crisis de mortandad de la historia.

Existen varios estudios sobre sus impactos sociales, económicos y políticos, uno de estos es el realizado por Beatriz Echeverri, quien argumenta en el prólogo de su libro que: “(...) en España murieron más de un cuarto de millón de personas, cifra solo comparable a la que se calcula que causó la guerra civil y, sin embargo, ha sido poco investigada" (Echeverri 1993:6).

Desde diversos campos de las ciencias sociales como la Antropología, la Sociología o la Economía Política, abundan algunos análisis importantes al estudio histórico de la enfermedad, lo cual ha permitido la introducción de un enfoque interdisciplinar en los mismos (Porras 1994). Los aportes de la Historia al conocimiento de esta y otras pandemias han sido fundamentales, y han fortalecido en el presente la reflexión y pensamiento crítico frente 
a estos acontecimientos, que hoy como ayer siguen trayendo muchas consecuencias en las poblaciones afectadas.

\section{PAPEL DE LA PRENSA Y POLÍTICAS PÚBLICAS}

Las investigaciones realizadas sobre esta pandemia no han podido establecer un consenso sobre el número de víctimas mortales, las cifras oscilan entre veinticinco y cincuenta millones. Esto equivale posiblemente al doble de las víctimas que produjo la Gran Guerra (19141918).

Este contexto hizo que muchos países no difundieran las noticias sobre su propagación por temor a que sus contingentes militares desertaran de los frentes de batalla. Solo España informó y previno a sus habitantes sobre la presencia expansiva de la gripe, aprovechando su condición de neutralidad dentro del conflicto. Esto dio a entender que solo ahí se había producido la propagación de la pandemia, de ahí que esta fue bautizada con el nombre de gripe española.

En lo que tiene que ver con su origen, existe un acuerdo alrededor de la existencia de dos principales hipótesis.

La primera ubica el inicio de la enfermedad en el Tíbet en 1917 y la segunda, de mayor aceptación entre los expertos, afirma que los primeros casos se presentaron más tarde, concretamente en el mes de marzo en 1918, en Kansas, EE.UU., entre los miembros del ejército estadounidense que preparaban su inminente traslado a Europa. El posterior desembarco de más de un millón de estos soldados en Francia fue decisivo para la devastadora propagación del virus. (Durán 2005:6)

Los militares norteamericanos originaron esta epidemia, sin embargo, la prensa y las autoridades norteamericanas nunca han reconocido el hecho, al defender reiteradamente ciertos intereses políticos. Inculpan que la enfermedad fue iniciada en territorios de Oriente, incluso nombran a China como su iniciadora. Más allá de todos estos conflictos, los síntomas comunes de esta gripe eran fiebre elevada, dolor de oídos, cansancio corporal, diarreas y vómito.

En la primera mitad de 1918 llegó a Europa. Las poblaciones más pobres y quienes estaban entre veinte a cuarenta años fueron los más afectados. La gripe provocó una mayor mortalidad en enfermos con tuberculosis pulmonar, así también puso en evidencia la escasa efectividad de los recursos médicos de la época (Duro y Tuells 2015)

El uso de mascarillas de tela empezó a ser fundamental para su control y propagación, especialmente, para quienes trabajaban en los organismos públicos. En el Viejo Continente, como se ha mencionado, la información no era transmitida por muchos gobiernos por su participación en el conflicto bélico. En países como Francia y Alemania las noticias eran parciales, tanto por la influencia de la guerra como por la falta de explicaciones científicas sobre su presencia.

Mientras se establecían teorías y se especulaba sobre los motivos de su aparición, esta empezó a propagarse de manera acelerada y trágica (Rodas 2017). Por lo expuesto y por las medidas tomadas para recuperarse de los efectos de la guerra, no se pudo crear un ambiente humanitario saludable con las condiciones necesarias para poder soportar los efectos de la pandemia.

En el caso de España, según Rodas (2017:6):

En gran parte del mes de octubre, particularmente en las tres primeras semanas, las noticias sobre la gripe fueron diarias y constantes; además publicadas en primera página (...) También se encontraron reportes de la situación epidemiológica en cada una de las provincias y regiones españolas.

La prensa española no solo se limitó a informar, sino que quiso contribuir a que la enfermedad no se propagara en su territorio, constituyéndose en una fuente informativa directa en Europa y otras 
regiones.

En el continente americano, por ejemplo, el papel de la prensa en Estados Unidos fue variando conforme el desarrollo de la enfermedad en el territorio. Tanto esta como sus gobernantes vieron a la gripe como un problema que sucedía en otros países (algo similar con el Covid-19) y su interés se centró en los pormenores que traía la Gran Guerra. Esto ocurrió en la primera ola de la pandemia, para la segunda (1919) otro fue su comportamiento, pues comunicaron a la población las medidas para evitar su propagación (Rodas 2017).

Hubo gran diferencia entre los roles asumidos tantopor la prensa española comonorteamericana. La primera brindó una información amplia y completa; la segunda solo se limitó a informar formas de prevención, sin hacer hincapié en que la gripe se expandía también en su territorio.

A nivel de América Latina, vale mencionar el papel cumplido por los medios argentinos locales y el de sus autoridades para impedir su propagación. En este país hay varios estudios, especialmente, desde una perspectiva salubrista, que muestran que la enfermedad tuvo más víctimas en las provincias del noroeste argentino, es decir, donde el esquema de desarrollo agroexportador tenía menos incidencia. Factores sociales y ambientales como falta de atención médica, hacinamiento e índices de analfabetismo, influyeron en una mayor presencia de la gripe (Carbonetti y Álvarez 2017).

La enfermedad llegó a este país vía inmigrantes europeos. En varias provincias del interior, sectores empobrecidos sufrieron una mayor mortalidad y el factor climático jugó un papel decisivo. El Departamento Nacional de Higiene dispuso la suspensión de reuniones masivas como espectáculos públicos, cierre de bares y restaurantes, procesiones y actos religiosos, así como la desinfección del transporte público, etc. (Carbonetti y Álvarez 2017). Algunas fueron acatadas, otras no, como las procesiones y misas, debido a cierto poderío de la Iglesia católica en algunas localidades.

En lo político empezaban a surgir los sindicatos de tendencia socialista y anarquista que organizaban a los obreros en los talleres de las ciudades y a los peones de los sectores rurales, esto dio paso a ciertos cambios y alta conflictividad social, alimentada por estudiantes universitarios en la ciudad de Córdoba, quienes impulsaban la histórica Reforma Universitaria de 1918 (Carbonetti, Rivero y Herrero 2014). Es en este contexto que la gripe española incide en la sociedad argentina, varios sectores se movilizan ante la poca presencia del Estado con medidas alternativas y ante el conservadurismo de la Iglesia.

En el caso de México, la mayoría de afectados por la epidemia fueron sectores indígenas $\mathrm{y}$ campesinos. Un punto de interés para este análisis es cómo la gripe logró diezmar a las tropas de Emiliano Zapata, lo que influyó en el desenlace de la Revolución mexicana, episodios recogidos en algunas investigaciones.

Francisco Pineda en su libro: La Guerra Zapatista 1916-1919, recoge testimonios que relatan la realidad del ejército rebelde: "Muchos se murieron de enfermedades, llegamos hasta tener una enfermedad que, dicen, se llama influenza española. También se murió mucha gente zapatista" (Pineda 2019:64). De esta manera los territorios insurgentes fueron invadidos no solo por la pandemia sino también por el hambre de soldados y población civil, quienes sucumbieron ante la falta de atención médica, alimentos y agua potable (Ávila 2020).

Miles de soldados zapatistas fallecieron, situación que obliga a las tropas a huir a las montañas y a abandonar las ciudades conquistadas. El ejército federal que combatía al zapatismo nunca pudo alcanzar estos logros, la presencia de la epidemia en las filas rebeldes ayudó a conseguirlos. Los campesinos fueron despojados de sus productos, de las tierras que habían trabajado, luego devueltas a los latifundistas. Una vez más vencía la lógica del capitalismo (agrario), ante la impotencia de las clases subalternas, ayudado por la presencia de un virus que misteriosamente frenó las fuerzas de la revolución (Ávila 2020).

En el caso de Ecuador, según el historiador 
Germán Rodas, la gripe española llega en diciembre de 1918 y estuvo presente hasta enero de 1919. Sus autoridades se adelantaron en los preparativos y pudieron dar las alertas necesarias, constatando su presencia en otros países, gracias a la información receptada en periódicos españoles y norteamericanos, que fue recogida por la prensa local, lo cual permitió a sus mandantes tomar las respectivas precauciones (Rodas 2017).

En una parte de su estudio, Rodas describe las condiciones sociales, económicas, higiénicas y ambientales que vivían la ciudad de Quito y el país, para poder establecer algunas diferencias entre la actitud del personal médico especializado y de las autoridades e instituciones de la época. Esto tuvo sus dificultades por el escaso material estadístico con el que se contaba (muy diferente a los tiempos actuales) para poder hacer un análisis más amplio de las implicaciones de la epidemia (Rodas 2015).

Rodas argumenta, además, la existencia en ese entonces en nuestro país de un "proyecto liberal civilista y plutocrático" (Rodas 2015:42), caracterizado por la presencia de gobiernos oligárquicos. Estos regímenes no pudieron continuar con las políticas salubristas implantadas por la Revolución alfarista (18951912). El Gobierno de Baquerizo Moreno (1916-1920), en materia de Salud Pública ordenó medidas puntuales que reafirmaban una política higienista pública de segundo grado, impulsada por médicos que se habían capacitado en Europa y que fueron retroalimentadas por las instituciones estatales (Rodas 2015).

Los diarios locales informaban de la propagación de la enfermedad en varias partes del mundo y alertaban de su peligrosidad y mortandad. Uno de los personajes de la historia ecuatoriana que cumple un papel fundamental en el combate a la enfermedad fue el doctor Isidro Ayora, quien luego de algunos años sería presidente de la República (1929-1931). Ayora lideró una serie de instrucciones epidemiólogas que provocaron una corta duración de la gripe en territorio ecuatoriano.
Gobiernos locales organizaron los Servicios de Asistencia Pública y fue difundida una Cartilla sobre la Gripe que cumple un rol fundamental en la información que la población debía saber para enfrentarla (Rodas 2015). Según Rodas la preocupación de las autoridades no solo fue la gripe, sino también la fiebre amarilla (Guayaquil) y la tifoidea (Quito).

Las autoridades llevaron a cabo un plan de contingencia y emergencia, efectuando fumigaciones $\mathrm{y}$ disponiendo que las boticas atendieran durante todo el día, y fueron subsidiadas por el Estado, por las Juntas de Beneficencia y por los municipios. Se orientaba cómo actuar con los enfermos, se activaron cocinas gratuitas y lazaretos temporales (Rodas 2015).

Como se evidencia en el caso ecuatoriano, la información proporcionada por los medios de comunicación locales sobre la situación de la gripe española en otros países fue fundamental para que el gobierno central y municipal pudieran implementar medidas de prevención en la población, así como disposiciones generales que coadyuvaron para que la enfermedad no tuviera efectos devastadores como sucedió en otros países, y para que su presencia en territorio ecuatoriano fuera por corto tiempo.

Tanto la peste negra como la gripe española trajeron consecuencias, enseñanzas sociales y sanitarias, y sirvieron de catalizadoras para transformaciones políticas y económicas. El análisis histórico debe reunir instrumentos para entender mejor los momentos actuales y fortalecer su lectura crítica. La peste negra contribuyó al debilitamiento del feudalismo y, a la vez, al fortalecimiento de la burguesía naciente. El sentido laico sobre la muerte debilitó el mito cristiano del paraíso, esencia fundamental para alterar las estructuras medievales de explotación.

En el caso de la gripe española, en algunos países provocó la insatisfacción con sus sistemas políticos, y despertó en las élites que, una nueva fase de acumulación capitalista debe procurar el cuidado higiénico y saludable de las masas trabajadoras, lo que en América Latina significó 
el traslado de esas ayudas sanitarias desde la filantropía a una acción estatal más eficaz. En síntesis, estas pandemias dieron paso a propuestas reformadoras, al mostrar problemas estructurales que no han sido solucionados.

\section{COVID-19 Y CRISIS DEL CAPITALISMO}

El mundo en los inicios de 2020 se ha visto afectado por la presencia de la Covid-19, una enfermedad producto del desarrollo de un virus parte de la familia de coronavirus. Muchas teorías han situado su origen en la ciudad de Wuhan en China. Unas más conspirativas que otras, que en el fondo no han ayudado a ver al problema epidemiológico desde una perspectiva real, que ayude a los gobernantes a tomar acciones más coherentes.

Todas estas teorías no han permitido fortalecer los sistemas democráticos, bajando la credibilidad de medios independientes, los que han hecho grandes esfuerzos para mostrar la verdad sobre esta pandemia. En fin, estas teorías han restado capacidad de análisis sobre las debilidades reales del sistema capitalista para enfrentar la crisis. Esto último no es reciente y ha puesto un escenario al cual se debe ir dando respuestas concretas desde todos los sectores y desde la acción decidida de los espacios subalternos.

\section{DEBILIDADES SISTÉMICAS Y COVID-19}

Desde que Donald Trump asume la presidencia de los EE. UU en 2017, las políticas neoliberales volvieron a tener fuerza en algunos gobiernos del orbe. La situación actual por efectos del coronavirus ha develado las debilidades de este modelo caracterizado por sostener políticas de carácter conservador y ultraderechista.

Una de las grandes verdades de esta pandemia es que este paradigma ha llevado a los países que lo adoptaron a una crisis social profunda. El capitalismo en su forma neoliberal ha entrado o mejor aún, viene de una larga crisis al ser incapaz de resolver los problemas socio-económicos de las mayorías, y por el contrario beneficia a una pequeña élite.

Esta crisis sistémica viene profundizándose desde 2008, y su característica principal habría radicado en una crisis de sobreproducción y sobreacumulación, relacionada con la reducción de la capacidad de consumo de los sectores populares (Thwaites 2010). El capitalismo desarrolló una significativa capacidad productiva que terminó rebasando las posibilidades de consumo de la mayoría de la población debido a la desigualdad social. La transferencia de recursos de estos sectores a una capa mínima beneficiaria seguiría siendo la dinámica neoliberal hasta hoy.

La salida a la crisis en 2008 tuvo el apoyo de la economía China que estaba en avanzada. El sector financiero asiático también fue afectado por la situación originada en Occidente, pérdida de puestos de trabajo, congelación de salarios; es decir, las economías asiáticas jugaron un papel importante para que China no se viera afectada por la crisis y viceversa (Thwaites 2010).

La estrategia de China ha sido construir su propio modelo y no depender de un país, de una región o de un solo producto, en cambio, economías como las de EE. UU., Reino Unido, Japón, entraron en una crisis que se ha extendido hasta los últimos años. Es en este contexto, de fortalecimiento del capitalismo de Estado de China y del agotamiento del neoliberalismo globalizado, que aparece el coronavirus.

El caso más significativo son los EE. UU., la política económica llevada a cabo por el gobierno ultraderechista de Trump ha empujado a que más de 30 millones de personas no dispongan de seguro médico y que los servicios de salud se hayan vuelto personalizados. Según algunos análisis, desde décadas atrás, "Europa Occidental y los Estados Unidos vienen construyendo un modelo societal que se preocupa por reducir y desmontar significativamente las capacidades del Estado para llevar a cabo políticas que mejoren los servicios de salud y educación 
públicos" (Ciappina 2018:2).

Estados Unidos y Brasil se disputan(al27 de mayo de 2020) el primer lugar en muertes y contagios por Covid-19, esto coincide con la actitud de sus gobernantes al no acatar las medidas de previsión dispuestas por la Organización Mundial de la Salud (OMS), y también por sus modelos ultraconservadores de política económica. En el caso de EE. UU., según una última investigación de la Universidad de Columbia en Nueva York, más de 35000 muertes se hubiesen evitado si las medidas de distanciamiento social empezaban una semana antes de lo previsto (El Comercio 2020).

En el Brasil de Jair Bolsonaro, según Emir Sader, no existe una política gubernamental con capacidad de liderazgo para poder enfrentar la pandemia. Bolsonaro ha recurrido a los militares para combatirla, a cambio de desprenderse del personal de salud que venía actuando en primera línea. Sin resultados y con la subestimación de la enfermedad por parte del presidente, Brasil se ha convertido en el epicentro mundial de la pandemia (Sader 2020). Lo que está pasando en suelo brasileño es un auténtico genocidio, el fundamentalismo religioso y el fascismo político de Bolsonaro, con la complicidad de los militares, están llevando al país de la samba y del jogo bonito a una catástrofe.

El capitalismo global en su versión extrema neoliberal $y$ con tintes de fascismo se ha mostrado intrínsecamente imposibilitado de enfrentar con efectividad a la pandemia. A este momento le suplantará una crisis más profunda pues, sin otros miramientos, el mayor peligro que impone el coronavirus no es que infecte cada vez a más personas, sino que infecte a la economía y a los intereses de aquellos que la dirigen a nivel mundial.

Como ejemplo, la industria farmacéutica, a lo largo de la historia, nunca ha mostrado interés en la investigación de los coronavirus que han aparecido desde los años sesenta, para ellos no es rentable invertir ante una crisis de salud pública (Harvey 2020). En definitiva, el modelo de negocio que el capitalismo neoliberal aplicó a la salud pública no ha sido útil para combatir la emergencia mundial. Estos gobiernos al recortar los presupuestos para la atención y la investigación científica en salud, y en el caso de los EE. UU., también para lo relativo a cambio climático, han llevado este modelo a su fracaso.

El Covid-19 ha evidenciado rotundamente el abuso del consumo capitalista, y a la vez ha mostrado una especie de venganza de la naturaleza ante un maltrato burdo y abusivo del medio ambiente, todo esto producto de un extractivismo neoliberal violento y no regulado. Es preciso concluir esta parte planteando que resulta sintomático que los países menos neoliberales, China, Corea del Sur, Taiwán y Singapur, hayan cumplido otro papel en la emergencia y hayan superado la pandemia en mejor forma (Harvey 2020).

\section{AMÉRICA LATINA Y COVID-19}

Al momento de escribir este apartado, América Latina se ha convertido en una especie de epicentro de la pandemia mundial. La situación en sus diferentes países varía de acuerdo con el papel cumplido por sus diferentes gobiernos. El caso de Brasil es elocuente y ya lo hemos mencionado anteriormente. En efecto, son gobiernos de derecha los instalados en la mayoría de países de la región.

Entre 2002 y 2016, la presencia de gobiernos nacional-populares o también llamados progresistas generaron otro tipo de políticas, lo cual motivó algunas expectativas en los sectores populares. En los últimos años América Latina, con algunas excepciones, ha vivido el auge de gobiernos neoconservadores, lo cual ha significado el regreso de políticas económicas recesivas, el incremento de la pobreza y la desigualdad, así como formas expansivas de represión social (López 2016).

Miremos brevemente el modelo chileno, pues este país fue uno de los iniciadores de la aplicación de medidas de ajuste neoliberal con la dictadura de Pinochet (1973-1990). Aquí, en los meses 
anteriores al aparecimiento del coronavirus se desataban grandes movilizaciones populares en rechazo a más de treinta años de neoliberalismo, donde los sectores de salud y educación habían sido los más afectados. Con una educación casi privatizada, fueron los estudiantes (secundarios y universitarios) en su mayoría quienes se habían autoconvocado a esas protestas.

Con la presencia del Covid-19, esto no vino a detenerse, pues la respuesta del gobierno conservador de Sebastián Piñera no ha permitido efectivizar el combate a la pandemia, delegando a las Fuerzas Armadas el resguardo de la seguridad interior y la custodia de los servicios sanitarios (Riggirozzi 2020). En Chile como en otros países latinoamericanos existe en este contexto de pandemia una gran precarización laboral. La hubo antes, pero la emergencia la agudizó. El teletrabajo se ha convertido en una variada forma de explotación.

En Colombia, los sistemas de salud han mostrado también sus fracturas al momento de afrontar la emergencia sanitaria. Según Claudia Velásquez, presidenta del Consejo Nacional de Enfermería, la situación generada por el aparecimiento del coronavirus develó de una manera contundente la crisis del sistema de salud colombiano, considerada desde años atrás como una "enfermedad crónica" estructural, que en la actualidad alcanza niveles alarmantes (Velásquez 2020:1).

Los diferentes gobiernos neoliberales no supieron dar respuestas a estos problemas estructurales y hoy con la presencia de la pandemia la problemática se ha centrado en tres aspectos: condiciones laborales críticas del personal sanitario; insuficiente infraestructura física y humana en las instituciones de salud y deficiencia en los sistemas de aseguramiento de salud, lo que ha generado deudas millonarias al personal y propiciado situaciones de pauperización (Velásquez 2020).

En esta parte podemos concluir que, antes de la llegada de la pandemia a la región no existían las condiciones necesarias para enfrentarla. A esto se suma la existencia de otros aspectos que han dificultado aún más las posibilidades de afrontarla, uno de ellos es el endeudamiento externo, problema estructural que conspira contra las posibilidades de crecimiento económico, interfiere en la distribución de sus presupuestos y que se ha convertido desde hace muchos años en un condicionamiento a las soberanías de los estados latinoamericanos (Ciappina 2018).

Existen otros casos que salen de la perspectiva neoliberal y han afrontado la situación de otra manera y con resultados diferentes, podemos citar el caso de Argentina, Uruguay o Venezuela. Así también, en el resto de los países pueden existir variantes o situaciones similares respecto a las posiciones neoliberales, o como en el caso de la Cuba socialista y su larga tradición basada en el internacionalismo solidario.

El desenlace posible en la América Latina pos-pandemia va a depender de las propuestas políticas de sus gobiernos y sus bases socioeconómicas. También el escenario tendrá que ver con las condiciones en que los sectores subalternos quedarán para confrontar al capitalismo neoliberal o sucumbir ante la propuesta de un modelo en esa misma línea, más radical o menos agresivo.

\section{EL CASO ECUATORIANO}

El impacto que ha causado la Covid-19 en Ecuador y las respuestas desde el gobierno hay que verlos, haciendo un poco de historia, desde la política económica implementada por Rafael Correa. En efecto, los diez años del correísmo estuvieron marcados por muchos puntos negativos y pocos positivos; dentro de los segundos tenemos su franca oposición a las políticas del FMI y del Banco Mundial, así como en menor cauce a la injerencia imperialista de los EE. UU., lo cual no quería decir tener una posición anticapitalista.

Su crítica a la larga noche neoliberal y a todos los partidos políticos que la sostuvieron no necesariamente significaba que su política de gobierno haya estado exenta de esos 
acercamientos, pues su modelo extractivista y de alianza con ciertos empresarios dejaron ver las debilidades de su propuesta, acrecentadas con los varios casos de corrupción, abusos de poder y criminalización de la protesta social.

Lenin Moreno y su gobierno de empresarios permiten el regreso del neoliberalismo a través de ajustes sociales. Según un estudio realizado por la Universidad Central, en el país la inversión en salud pasó de USD 306 millones en 2017 a USD 201 millones en 2018 y USD 110 millones en 2019, lo que ha implicado una disminución del $34 \%$. A esto se suman medidas de austeridad y ajustes en el sector, implicando despidos de personal, menor gasto en insumos e infraestructura, y limitando su capacidad de atención (Báez 2020). Esto explica de manera estructural por qué el coronavirus afectó tanto al país, especialmente a Guayaquil, donde el índice de pobreza y pobreza extrema es del $17 \%$.

Al terminar el mes de marzo, Ecuador ocupaba el primer lugar en número de fallecidos en Sudamérica. Ante esto el gobierno salió al paso, culpando a la emigración española y a la población por los datos alarmantes, sin asumir la responsabilidad de su mal manejo de la crisis. Con el ejemplo de la gripe española en 1918, si hoy las autoridades centrales hubiesen tomado otra actitud y aplicaran un sistema de prevención, si se hubiesen destinado los recursos materiales y humanos en mejores condiciones, se habría afrontado la crisis con mayor eficacia.

Hicieron lo contrario y más bien se utilizó el momento de la crisis para tomar medidas de ajuste neoliberal: seguir bajando los presupuestos en salud y educación; cerrar o liquidar empresas públicas con los correspondientes despidos; flexibilización laboral, bajar sueldos y horas de trabajo; entregar al sector privado nacional o internacional el manejo de las empresas liquidadas.

Su pacto con las élites económicas nacionales y con el FMI y la insistencia del pago de la deuda externa en medio de la emergencia, se suman a las medidas implantadas por un gobierno que solo ha respondido a los intereses empresariales en detrimento de la mayoría del pueblo ecuatoriano, que se ha visto vulnerada en sus derechos e impedida de acceder a mejores condiciones de vida. Por lo expuesto anteriormente, el gobierno de Lenin Moreno en el contexto del coronavirus ha sido uno de los peor evaluados de la región.

\section{CONCLUSIONES}

El contexto ecuatoriano y mundial atravesado por la presencia de la COVID-19, ha permitido volver por momentos a los hechos que han dejado huella en la historia (peste negra-gripe española), mirarlos en sus respectivos contextos, analizarlos e interpretarlos, para ampliar desde una perspectiva crítica el conocimiento de su devenir histórico. Las dos pandemias más mortales de la historia dejaron sus huellas, mucha mortandad y miedo en las poblaciones que las soportaron.

Así también muchas lecciones y enseñanzas, pero sobre todo la necesidad de recurrir a cambios fundamentales a nivel estructural o social. La peste negra trajo un cambio radical muy importante, el feudalismo opresor de los campesinos devino en una sociedad moderna menos opresora y con más oportunidades para estos. El campo se transformó, sus productores fueron mejor pagados y sus productos mejor comercializados.

En la segunda década del siglo XX y como consecuencia de la gripe española, muchos adultos jóvenes murieron, especialmente en EE. UU., donde sus autoridades y medios de comunicación al inicio no informaron sobre la presencia y peligro de la gripe. En América Latina, en países como Argentina se enfrentó a la epidemia organizadamente a pesar de un clima de conflictividad social y política. En México, en cambio, la epidemia influyó en el desenlace de la Revolución mexicana, provocando muchas muertes en filas del ejército rebelde y en las poblaciones que lo apoyaban. 
En Ecuador, sus autoridades se informaron de su presencia a través de los medios y supieron organizar las medidas sociales $\mathrm{y}$ sanitarias pertinentes para aplacar los efectos mortales de la gripe. En el campo de la Salud Pública, en varios países se vio la necesidad de fortalecer y transformar sus sistemas sanitarios e instituciones. La cooperación internacional se vio fortalecida y el término distanciamiento social adquirió importancia estratégica como medida para combatir las epidemias.

La presencia de la pandemia COVID-19, en los inicios de 2020, marca también un momento histórico en el planeta por todas las consecuencias que ha dejado, así también, por las críticas a las formas de sobrellevarla en diferentes países. Sus efectos evidenciaron la crisis sistémica del capitalismo en su forma neoliberal, crisis que lo venía arrastrando desde años atrás y que ahora se ha profundizado ante la ineficacia de los gobiernos que lo sostienen, para poder enfrentar a la pandemia de forma más contundente.

La peste negra albergó el término cuarentena en la Italia medieval, el distanciamiento social se aplicó con la presencia de la gripe española y marcó la necesidad de una preocupación real por los sistemas de salud. El capitalismo nunca le ha dado la importancia debida a este campo y ahora la COVID-19 está presente en medio de una precarización de la salud y del control sanitario, $\mathrm{y}$ ante el negacionismo de gobiernos como EE. UU. y Brasil. La crisis del coronavirus ha sido mortal para el neoliberalismo, reconociendo la necesidad de Estados más fuertes, con capacidad para satisfacer los principales derechos sociales.

Una de las tareas será separar el poder privado del político público, en la procura de un progreso económico de nuestros países y el bienestar social de sus mayorías.

DECLARACIÓN DE CONFLICTOS DE INTERESES: El autor declara no tener conflicto de interés.

\section{REFERENCIAS BIBLIOGRÁFICAS}

Ávila, A. (4 de mayo de 2020). La gripe española y la derrota de Emiliano Zapata. América Latina en Movimiento. Recuperado de https://www.alainet.org/ es/articulo/206345

Báez, J. (28 de marzo de 2020). Los recortes cobran factura al Ecuador: La inversión en salud se redujo un $36 \%$ en 2019. IIE. Recuperado de https://coyunturauceiie. org/2020/03/28/1os-recortes-cobranfactura-al-ecuador-la-inversion-ensalud-se-redujo-un-36-en-2019/

Benedictow, O. (2011). La Peste Negra, 13431356: La historia completa. Madrid, España: Ediciones AKAL.

Carbonetti, A. y Álvarez A. (2017). La Gripe Española en el interior de la Argentina (1918-1919). Americania. Revista de Estudios Latinoamericanos, (6), 207229. Recuperado de https://www.upo. es/revistas/index.php/americania/article/ view/2325/2329

Carbonetti A., Rivero D. y Herrero M. (2014). Políticas de salud frente a la gripe española y respuestas sociales. Una aproximación a los casos de Buenos Aires, Mendoza y Salta a través de la prensa (1918-1919). Astrolabio, (13), 66-96. Recuperado de https://ri.conicet. gov.ar/bitstream/handle/11336/36865/ CONICET_Digital_Nro.e73193e75690-4e27-a50c-9a4656792d33 A. pdf? sequence $=2 \&$ isAllowed $=y$

Ciappina C. (2018). Crisis del coronavirus: la pandemia global y las disputas de sentido. ¿La configuración de un orden nuevo? Una mirada desde América Latina. Questión; Incidentes III. Parte I: Análisis/Consecuencias, 1, 1-12.doi: 
https://doi.org/10.24215/16696581e280

Durán, M. (2005). La gripe española en Bogotá: la epidemia de 1918 (tesis de grado). Pontificia Universidad Javeriana, Bogotá, Colombia. Recuperado de https://repository.javeriana.edu. co/bitstream/handle/10554/49032/ La\%20 gripa \%20espa\%c3\%b1 ola $\% 20$ e n $\% 20$ B o g o t $\%$ c $3 \%$ a $1 . \% 20$ La\%20epidemia\%20de\%201918. pdf?sequence $=1 \&$ isAllowed $=\mathrm{y}$

Duro, J. y Tuells, J. (2015). La gripe española según el diario España Médica (19181919). Vacunas, 16(2), 81-86. doi: https:// doi.org/10.1016/j.vacun.2015.07.007_

Echeverri, B. (1993). La Gripe Española. La pandemia de 1918-1919. Madrid: CIS.

Haindl, A. (2010). La Peste Negra. Arqueología, historia y viajes sobre el mundo medieval, (35), 56-69.

Harvey, D. (22 de marzo de 2020). Política anticapitalista en tiempos de Covid-19. SinPermiso. Recuperado de https://www. sinpermiso.info/printpdf/textos/politicaanticapitalista-en-tiempos-de-covid-19

López, F. (2016). América Latina, crisis del posneoliberalismo y ascenso de la nueva derecha. Buenos Aires, Argentina: CICCUS-CLACSO.

Más de 35000 muertes podrían haberse evitado si el confinamiento empezaba una semana antes en EE.UU. (21 mayo de 2020). El Comercio, p. 1. Recuperado de https://www.elcomercio.com/actualidad/ muertes-evitadas-confinamientotemprano-eeuu.html

Pineda, F. (2019). La Guerra Zapatista 19161919. México: Era. Recuperado de https:// www.edicionesera.com.mx/media/ ediciones_era/files/sample-93787.pdf

Porras, M. (1994). Una ciudad en crisis: la epidemia de gripe de 1918-19 en Madrid (tesis de doctorado). Universidad Complutense, Madrid, España. Recuperado de https://eprints.ucm. es/2765/1/T19405.pdf

Riggirozzi. P. (2020). Coronavirus y el desafío para la gobernanza regional en América Latina. Análisis Carolina, (12), 1-13. Recuperado de https:// www.fundacioncarolina.es/wp-content/ uploads/2020/03/AC-12.2020.pdf_

Rodas, G. (2015). Historia de la "gripe española" que llegó a Quito en 1918 (informe de investigación). Universidad Andina Simón Bolívar, Quito, Ecuador. Recuperado de http://repositorio.uasb. edu.ec/bitstream/10644/4705/6/PI-201529-Rodas-Historia.pdf

Rodas, G. (2017). La Gripe Española: la información de la prensa española y norteamericana que alertó la epidemia en el Ecuador y el rol del médico Isidro Ayora. Americania. Revista de Estudios Latinoamericanos, (6), 136-166. Recuperado de https://rio.upo.es/xmlui/ bitstream/handle/10433/5282/23869120-1-PB.pdf?sequence

Romano, R. y Tenenti, A. (1977). Los fundamentos del mundo moderno. Edad Media tardía, Renacimiento, Reforma. España: Siglo XXI Editores. Recuperado de http://www.unsa.edu. ar/histocat/hamoderna/53706196-LosFundamentos-Del-Mundo-ModernoRomano-Tenenti.pdf

Sader, E. (25 de mayo 2020). Bolsonaro y los militares llevan a Brasil al epicentro de la pandemia. Rebelión. Recuperado de https://rebelion.org/bolsonaro-y-losmilitares-llevan-a-brasil-al-epicentromundial-de-la-pandemia/

Simoni, K. (2007). De peste e literatura: imagens do Decameron de Giovanni Boccaccio. Anuário de Literatura, 12(12), 
31-40. doi: https://doi.org/10.5007/\%25x

Tomasi, S. (2020). Historia de las pandemias mundiales y la economía. Argentina: Magaten. Recuperado de http://www. magatem.com.ar/HISTORIA-DE-LASPANDEMIAS-MUNDIALES-Y-LAECONOMIA.pdf

Thwaites, M. (2010). Después de la globalización neoliberal. ¿Qué estado en América Latina? OSAL, XI(27), 19-43. Recuperado de http://biblioteca.clacso. edu.ar/ar/libros/osal/osal27/05Thwaites. pdf

Velásquez, C. (2020). Enfermería en Colombia en tiempos de la pandemia por Coronavirus. Ciencia y Cuidado, 17(1), 5-7. Recuperado de: https://revistas. ufps.edu.co/index.php/cienciaycuidado/ article/view/2332/2323 